Review

\title{
Effect of Targeted Agents on the Endocrine Response of Breast Cancer in the Neoadjuvant Setting: A Systematic Review
}

\author{
Antonino Grassadonia ${ }^{1,2}{ }^{凶}$, Marta Caporale ${ }^{2}$, Nicola Tinari ${ }^{1,2}$, Marinella Zilli², Michele DeTursi ${ }^{1,2}$, Teresa \\ Bio-Oncologia) \\ 1. Department of Medical, Oral and Biotechnological Sciences, University "G. D'Annunzio", Chieti, Italy \\ 2. Medical Oncology Unit, "SS. Annunziata" Hospital, Chieti, Italy \\ 3. Department of Oncology, “S.S. Trinita'” Hospital, Sora, Italy \\ 4. Division of Medical Oncology B, Regina Elena National Cancer Institute, Rome, Italy
} Gamucci ${ }^{3}$, Patrizia Vici ${ }^{4}$, Clara Natoli ${ }^{1,2}$ on behalf of CINBO (Consorzio Interuniversitario Nazionale per la

$\triangle$ Corresponding author: Antonino Grassadonia, email: grassadonia@unich.it, telephone +390871 3556732, fax +390871 3556707

(๑) 2015 Ivyspring International Publisher. Reproduction is permitted for personal, noncommercial use, provided that the article is in whole, unmodified, and properly cited. See http://ivyspring.com/terms for terms and conditions.

Received: 2015.01.11; Accepted: 2015.03.02; Published: 2015.05.12

\begin{abstract}
Inhibition of aberrantly activated pathways cross-talking with hormone receptor (HR) improves response to endocrine therapy in patients with HR-positive advanced breast cancer. We performed a Pubmed database systematic review to ascertain the existence of a better clinical response when combining endocrine therapy with targeted agents in the neoadjuvant setting. Preclinical studies or trials evaluating toxicity were excluded.

We found nine phase II trials that fulfilled the research criteria. The endocrine agents used were third generation aromatase inhibitors (Als), anastrozole, letrozole or exemestane. The investigated targeted agents were inhibitors of tyrosine kinase receptors such as gefitinib, imatinib or trastuzumab/lapatinib, inhibitors of mTOR, such as everolimus, inhibitors of COX-2, such as celecoxib, and inhibitors of angiogenesis, such as bevacizumab. The response rate (RR) observed combining endocrine and targeted agents ranged between $36 \%$ and $90 \%$.

Overall the studies failed to show a remarkable advantage in RR in the combination group compared to historical control subjects receiving Als alone.
\end{abstract}

Key words: breast cancer; neoadjuvant endocrine therapy; targeted therapy; clinical response

\section{Introduction}

Neoadjuvant systemic therapy is strategically used to reduce the primary breast cancer volume and allow either surgery in patients initially judged inoperable [1-3], or conservative surgery in patients who otherwise would have received mastectomy [3, 4-6].

Long-term outcomes of pre- and post-operative therapy are comparable [4, 7-9], but the neoadjuvant approach gives additional information on the antitumor activity of the therapeutic agents and provides a precious biological system, the tumor itself, to study "in vivo" the possible mechanisms involved in the occurrence of resistance. Moreover, patients who achieve a pathologic complete response ( $\mathrm{pCR}$ ) after neoadjuvant treatment, i.e. absence of cancer in breast and nodes, have a very good prognosis $[10,11]$. In this scenario, chemotherapy is usually the first choice of treatment for its ability to reach higher rates of $\mathrm{pCR}$, while endocrine therapy is usually reserved for elderly patients with hormone receptor (HR)-positive tumors and affected by comorbidities. 
Nevertheless, in recent years, neoadjuvant endocrine therapy is increasingly used as primary systemic therapy for postmenopausal women with HR-positive tumors given that this subgroup of patients achieves a low rate of $\mathrm{pCR}$ with chemotherapy and maintains, in any case, a favourable long-term outcome [12-16]. In addition, no prognostic advantage from the attainment of $\mathrm{pCR}$ has been observed in patients with HR-positive tumors [17].

In the neoadjuvant setting, tamoxifen has historically been employed, but the third generation aromatase inhibitors (AIs), including letrozole, anastrozole and exemestane, have been shown to be significantly superior to tamoxifen in terms of overall response rate (RR) and achievement of breast-conserving surgery [18-21].

As for other anti-cancer treatment, tumor might exhibit de novo or acquired resistance to endocrine therapy. The underlying mechanisms are not completely understood, but a major role seems to be played by cross-talks between HR and intracellular signaling triggered by tyrosine kinase receptors (TKRs) [22, 23]. The activation of these molecular pathways might affect tumor response to endocrine therapy. In fact, in preclinical studies, the overexpression of human epidermal growth factor receptor 2 (HER2) in tumor cells significantly reduces the activity of endocrine therapies [24-26]. Similarly, the epidermal growth factor receptor (EGFR) has been associated with endocrine-resistant phenotype [27], and platelet-derived growth factor receptor (PDGFR) has been shown to be associated with biological aggressiveness of breast cancer [28]. Among the downstream pathways activated by TKRs, the phosphoinositide-3-kinase (PI3K)/Akt signaling pathway, including the mammalian target of rapamycin (mTOR), has been showed to be involved in the resistance of breast cancer cells to endocrine therapy $[29,30]$. Moreover, tumor cells might secrete pro-angiogenic factors, such as the vascular endothelial growth factor (VEGF), that in some way could limit hormone therapy efficacy. For example, in animal models the overexpression of VEGF in tumor cells is responsible for tamoxifen resistance [31]. In this altered molecular milieu the inhibition of a driver pathway by specifically designed agents (targeted agents) can restore hormone sensitivity [32-34].

Notably, in some cases, the preclinical research has been translated into clinical practice after confirmatory phase III clinical trials. In particular, the combination of an AI with anti-HER2 drugs, such as trastuzumab or lapatinib, has been demonstrated to achieve longer progression free survival compared to AI alone in postmenopausal women with metastatic HER2-positive breast cancer $[35,36]$. In another study, the Bolero-2 trial, the combination of everolimus, a mTOR inhibitor, and exemestane resulted in an increased efficacy compared to exemestane alone in patients with HER2-negative advanced breast cancer who progressed to non-steroidal AI [37].

Differently from the metastatic setting, the neoadjuvant setting is a unique opportunity to assess the relative endocrine sensitivity of a tumor never exposed to a previous hormonal treatment and, therefore, might provide insights on the molecular mechanisms involved on the early occurrence of resistance.

The strong rationale and the clinically established benefit of adding a targeted agent to endocrine therapy in metastatic breast cancer prompted us to carry out a systematic review to evaluate a possible advantage of the combination also in the neoadjuvant setting, where a tumor shrinkage is often required to avoid mastectomy.

\section{Methods}

\section{Study Selection}

A search of PubMed database on studies combining endocrine therapy with targeted agents in the neoadjuvant setting of breast cancer and published from November 2004 to November 2014 was performed. To limit the research to articles that fulfilled the criteria of "neoadjuvant", "endocrine therapy" and "clinical trials" we used the sorting key words according to the following algorithm: "breast cancer AND (neoadjuvant OR neo-adjuvant OR pre-operative OR preoperative OR induction) AND (clinical trial OR randomized controlled trial OR random OR randomized) AND (tamoxifen OR anastrozole OR exemestane OR letrozole OR aromatase inhibitors OR fulvestrant OR antiestrogens)". Further selection was made by choosing "clinical trials" and "last 10 years" in the PubMed database filters. The remaining articles were singly evaluated for pertinence to our objectives.

\section{Exclusion Criteria}

In vitro experiments and animal studies were excluded. Trials that assessed only toxicity (phase I studies) or that included chemotherapy agents in the treatment plan were also excluded.

\section{Response Evaluation}

All the studies described herein evaluated clinical response after the neoadjuvant treatment [38-46]. Breast palpation, ecography or mammography were arbitrarily utilized. If not otherwise indicated we refer response to caliper measurements. The clinical response was defined according to the Response Evaluation Criteria in Solid Tumors (RECIST) [38, 40, 43 46] or the Union International Centre Cancer (UICC) 
criteria [39, 41, 44, 45]: complete response (CR), partial response (PR), stable disease (SD), and progressive disease (PD). One study did not provide the evaluation criteria [42].

\section{Results}

The trial selection algorithm is illustrated in Fig. 1. Pubmed database showed a list of 476 articles. Many of them (225) were excluded for the lack of a clinical trial design. In order to focus on the most active endocrine agents currently used in the treatment of breast cancer, we limited the research to the last 10 years. Of the 119 articles resulted by the above restrictions, only 9 dealt with objective response rate (RR) [38-46]. As shown in Table 1, all papers were phase II studies, 4 randomized and 5 non-randomized, incorporating an $\mathrm{AI}$ as endocrine agent. In one study fulvestrant was used as well [40]. The table summarizes the types of agent investigated, the period of treatment and the clinical response observed in the studies. The targeted agents utilized in combination with AIs included inhibitors of TKRs, such as gefitinib [38-40], imatinib [41], or trastuzumab/lapatinib [42]; inhibitors of mTOR, such as everolimus [43]; inhibitors of Cox-2, such as celecoxib [44, 45]; inhibitors of angiogenesis, such as bevacizumab [46]. The details of the studies, with particular regard to clinical response, are described below.

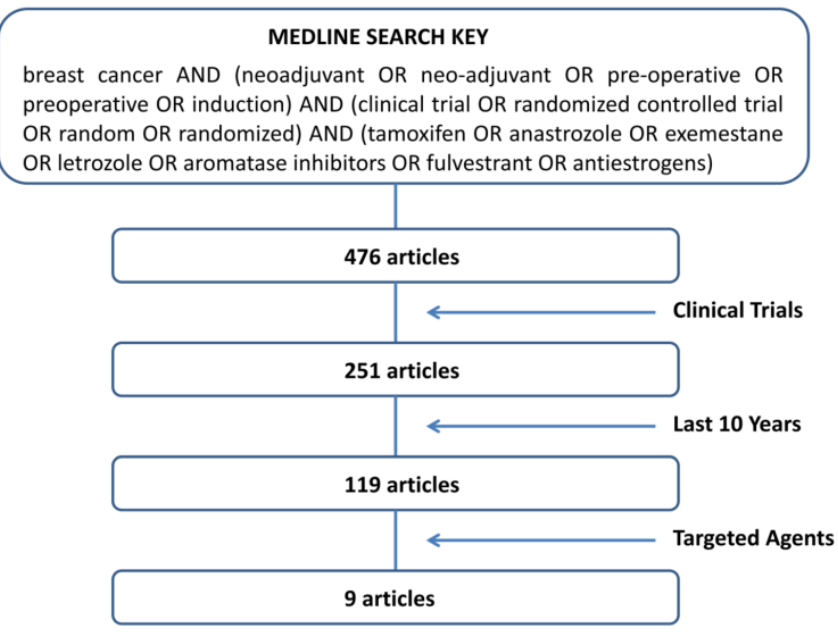

Fig. 1. The sorting key words entered on PubMed and the algorithm followed to select the studies.

\section{Inhibitors of TKRs}

Gefitinib, a small molecule blocking the tyrosine kinase domain of EGFR, was tested in three different studies. In the first study [38], patients with HR-positive and EGFR-positive breast cancer were randomized to receive gefitinib $250 \mathrm{mg}$ daily associ- ated with anastrozole $1 \mathrm{mg}$ daily (27 patients) or gefitinib alone (29 patients) for 4-6 weeks. The RR in the combination group was $67 \%$, not significantly different from gefitinib alone (79\%), although the combination was more effective in reducing Ki67 labeling index. No pCR was observed. The study does not provide information on the basal activity of anastrozole given that the control arm was gefitinib.

Table 1. Phase II studies reporting data on clinical response to neoadjuvant therapy combining Als with targeted agents

\begin{tabular}{|c|c|c|c|c|c|c|c|}
\hline \multirow[t]{2}{*}{ Study } & \multirow[t]{2}{*}{$\mathrm{R}$} & \multirow[t]{2}{*}{$N$} & \multirow{2}{*}{$\begin{array}{l}\text { Period } \\
\text { (weeks) }\end{array}$} & \multicolumn{4}{|c|}{ Clinical Response (\%) } \\
\hline & & & & CR & PR & SD & PD \\
\hline Polychronis 2005 [38] & Yes & & & & & & \\
\hline Gefitinib & & 29 & $4-6$ & 17 & 62 & 10 & 0 \\
\hline Gefitinib + ANA & & 27 & $4-6$ & 26 & 41 & 26 & 0 \\
\hline Smith 2007 [39] & Yes & & & & & & \\
\hline ANA & & 85 & 16 & 4 & 57 & 33 & 4 \\
\hline ANA + Gefitinib & & 31 & 16 & 7 & 40 & 37 & 5 \\
\hline ANA $\rightarrow$ ANA + Gefitinib & & 90 & $2 \rightarrow 14$ & & & & \\
\hline Massarweh 2011 [40] & No & & & & & & \\
\hline $\begin{array}{l}\text { ANA+ Fulvestrant + } \\
\text { Gefitinib }\end{array}$ & & 12 & 16 & 17 & 25 & 42 & 17 \\
\hline Chow 2008 [41] & No & & & & & & \\
\hline LET + Imatinib & & 10 & 12 & 0 & 90 & 10 & 0 \\
\hline Rimawi 2013 [42] & No & & & & & & \\
\hline $\begin{array}{l}\text { LET+Trastuzumab+ } \\
\text { Lapatinib }\end{array}$ & & 39 & 12 & & 46 & 54 & 0 \\
\hline Baselga 2009 [43] & Yes & & & & & & \\
\hline LET & & 138 & 16 & 9.1 & 50 & 29.5 & 9.8 \\
\hline LET + Everolimus & & 132 & 16 & 13 & 55.1 & 24.6 & 4.3 \\
\hline Chow 2008 [44] & Yes & & & & & & \\
\hline EXE + Celecoxib & & 30 & 12 & 10 & 48.6 & 40.5 & 0 \\
\hline EXE & & 24 & 12 & 4 & 50.5 & 45 & 0 \\
\hline Letrozole & & 28 & 12 & 2 & 60 & 38 & 0 \\
\hline Lustberg 2011 [45] & No & & & & & & \\
\hline $\mathrm{EXE} \rightarrow \mathrm{EXE}+$ Celecoxib & & 22 & $8 \rightarrow 8$ & 0 & 36 & 55 & 5 \\
\hline Forero-Torres 2010 [46] & No & & & & & & \\
\hline LET + Bevacizumab & & 25 & 24 & 16 & 52 & 16 & 8 \\
\hline
\end{tabular}

The second study [39] randomized 236 women and provided similar results, reporting RRs of $47 \%$ and $61 \%$ in the combination group (121 patients) and anastrozole alone group (85 patients), respectively. However, the primary endpoint of the study was the change of Ki67 evaluated in tumor core biopsy after 2 weeks and after 16 weeks of treatment. The authors hypothesized that lack of Ki67 reduction after 2 weeks could identify patients whose tumor was resistant to anastrozole and that might be particularly sensitive to the added gefitinib. For this reason the combination group was divided into a group of patients receiving gefitinib $250 \mathrm{mg}$ daily for 16 weeks and a group receiving placebo for 2 weeks, followed by gefitinib 250 mg daily for 14 weeks. The study failed to demonstrate any gefitinib-related difference in both Ki67 reduction and $R R$. 
The third study [40] examined the activity of gefitinib $250 \mathrm{mg}$ daily associated with a potential more effective endocrine treatment combining anastrozole 1 mg daily and fulvestrant $250 \mathrm{mg}$ intramuscular monthly for 16 weeks. The study enrolled 15 patients, 3 of whom withdrew before response assessment. In the remaining 12 patients, RR was only $37 \%$. Rate of pCR was not reported.

Imatinib, a potent inhibitor of PDGFR and cKit, was studied in combination with letrozole in a pilot study enrolling 13 women [41]. Patients received preoperatively imatinib $400 \mathrm{mg}$ twice daily and letrozole $2.5 \mathrm{mg}$ daily for 3 months. Three patients withdraw after 8 weeks because of hematoma in tumor or toxicity. Nine out of 10 evaluable patients $(90 \%)$ obtained a PR and $1(10 \%)$ had SD. One patient $(10 \%)$ achieved a pCR.

The dual block of HER2, obtained with trastuzumab and lapatinib, was studied in 64 patients with locally advanced HER2-positive breast cancer [42]. Patients received trastuzumab weekly $(4 \mathrm{mg} / \mathrm{kg}$ loading, then $2 \mathrm{mg} / \mathrm{kg}$ ) and lapatinib $1000 \mathrm{mg}$ daily for 12 weeks. Thirty-nine patients whose tumors were HR-positive were also treated with letrozole $2.5 \mathrm{mg}$ daily. The study primary endpoint was the rate of pCR, which was $18 \%$ in the HR-positive group and $28 \%$ in the HR-negative group. No data were reported for clinical response, except for a table showing a RR (referred to as non-pCR) of $46 \%$ in the letrozole group. Moreover, given that only two patients experienced progression during the study treatment and both were in the HR-negative group, we can extrapolate that $54 \%$ of patients in the letrozole group had SD.

\section{Inhibitors of $\mathbf{m T O R}$}

A phase II, randomized, double-blind, placebo-controlled trial was carried out to evaluate the rate of tumor response combining everolimus and letrozole in the neoadjuvant treatment of postmenopausal women with HR-positive breast cancer [43]. One hundred thirty-eight patients received letrozole 2.5 mg plus everolimus $10 \mathrm{mg}$ daily, while 132 received letrozole plus placebo. Treatment was administered for 16 weeks. The RRs were $68.1 \%$ in patients treated with everolimus and $59.1 \%$ in patients treated with placebo $(\mathrm{p}=0.062)$, a difference considered statistically significant in the one-sided $\chi^{2}$ test. Moreover, the combination arm showed a higher proportion of Ki67 index reduction $(57 \%$ vs $30 \%, \mathrm{p}<0.01)$. As expected, the everolimus group had a higher incidence of grade 3 and 4 toxicity compared with the placebo one $(22.6 \%$ vs $3.8 \%$ ), and a dose reduction or interruption was required in $52.9 \%$ of cases (vs $7.6 \%$ in the placebo treated patients). A pCR was reported in two patients treated with everolimus and in one treated with pla- cebo.

\section{Inhibitors of COX-2}

We found two trials combining AIs with celecoxib, a cyclooxygenase-2 (COX-2) inhibitor. The first study [44] randomized 82 patients into 3 groups: group A (30 patients) received exemestane $25 \mathrm{mg}$ daily and celecoxib $400 \mathrm{mg}$ twice daily, group B (24 patients) received exemestane $25 \mathrm{mg}$ daily, group $\mathrm{C}$ (28 patients) received letrozole $2.5 \mathrm{mg}$ daily. The overall RRs were $58.6 \%$ for group A, $54.5 \%$ for group $\mathrm{B}$ and $62.0 \%$ for group C. No significant differences were observed among the three groups, but the combination group included $20 \%$ of patients with HER2-positive disease, a molecular phenotype expressed in only $7 \%$ and $8 \%$ of patients of group $B$ and $\mathrm{C}$, respectively. Moreover, group A showed the highest clinical CR (10\%). A pCR was observed only in two $(7 \%)$ patients of group C.

In the second study [45] 22 postmenopausal women were enrolled and treated with neoadjuvant exemestane $25 \mathrm{mg}$ daily for 8 weeks, followed by exemestane $25 \mathrm{mg}$ daily and celecoxib $400 \mathrm{mg}$ twice daily for 8 weeks. The study had this design because its primary objective was the assessment of changes in the expression of the aromatase enzyme, as well as estrogen receptor, progesterone receptor, HER2, Ki67, and COX-2 in the tumor before, during, and after treatment. The study showed that progesterone receptor and Ki67 significantly decreased by effect of the AI alone (8 weeks) and continued to reduce during combination therapy; estrogen receptor and COX-2 decreased only after combination therapy (16 weeks); HER2 and aromatase enzyme were not affected by treatment. The RR, evaluated at the end of treatment, was $36 \%$. No patient obtained a clinical CR or $\mathrm{pCR}$.

\section{Inhibitors of angiogenesis}

A single-arm pilot study was carried out to assess the activity of the combination of letrozole and bevacizumab, a monoclonal antibody inhibiting VEGF, in the neoadjuvant treatment of postmenopausal women with HR-positive breast cancer [46]. Twenty-five patients received letrozole $2.5 \mathrm{mg}$ daily and intravenous bevacizumab $15 \mathrm{mg} / \mathrm{kg}$ every 3 weeks. An objective clinical response was observed in 17 of 25 patients $(68 \%)$, with 4 CR $(16 \%)$ and 13 PR (52\%). Three out of 4 clinical CR were also pCR $(12 \%)$.

\section{Discussion}

We performed a systematic literature review aimed at assessing if the addition of targeted agents might overcome endocrine resistance and improve clinical response in women with a recent diagnosis of 
breast cancer treated preoperatively with endocrine therapies. To evaluate the anti-tumor activity of the investigated treatment we focused on clinical response rather than $\mathrm{pCR}$ because of the low $\mathrm{pCR}$ rate achieved with endocrine therapy, especially in a short-term treatment.

We found 9 articles that fulfilled the research criteria. All of them were phase II studies that utilized third generation AIs, in one study combined with fulvestrant, as endocrine agents. Historically, in the neoadiuvant setting, patients treated with AIs achieve RRs ranging between $37 \%$ and $70 \%$ [18-21]. In the impossibility to make a rigorous meta-analysis of the selected studies, due to small sample size, different duration of treatment and different types of targeted agents, and with the limitations inherent in phase II trials to provide valid conclusions due to selection and confounding biases, we speculate that $70 \%$ might be set as a reasonable RR threshold required to presume a clinical benefit of the combination therapy. In our clinical practice we obtained even a higher RR (86\%) with neoadjuvant AIs [47].

Overall, the selected studies failed to demonstrate an advantage with added targeted agents over AIs alone. Figure 2 provides an overview of the RR obtained in each trial, and shows how much this value differs from the expected RR (shaded area). It is clear that in all studies but one, RR is within the estimated range, i.e. no advantage. The only study showing an impressive increase of response was the one combining letrozole and imatinib (RR 90\%) [41]. However, the study has a very small sample size (10 patients evaluable for response) to allow any firm conclusion. Notably, in this study three patients withdrew for toxicity: one patient developed tumor hematoma and underwent surgery prematurely, two patients experienced acute coronary syndrome and generalized edema. If we recalculate RR on the "intention to treat" population rather than on the evaluable patients, it decreases to $69 \%$, i.e. in the range of no benefit. However, the high RR observed combining imatinib and AI suggests further investigation, advisably with a dose less than $400 \mathrm{mg}$ twice daily (the dose administered in the study), to reduce the potential risk of severe toxicity.

The overall unsatisfactory results observed adding preoperatively targeted agents to AIs is quite surprisingly considering the plethora of preclinical studies and the encouraging results in metastatic patients that indicate a synergistic effect. We try to argue possible explanations.

First, except for the study on trastuzumab/lapatinib [42] and one study on gefitinib [38] in which the expression of HER2 and EGFR in tumor tissue were evaluated, respectively, the tar- geted agents were utilized without patient selection for a specific molecular target. It is evident that only tumors expressing the functionally altered molecule (the target) might respond to the treatment. Moreover, it is likely that even when a target is identified and the right population selected to be treated, only a proportion might receive a benefit because of unknown co-existing molecular alterations that retain tumor resistance. Therefore, in a heterogeneous population of HR-positive breast cancer it is conceivable that small dimensioned phase II studies might fail their primary endpoint.

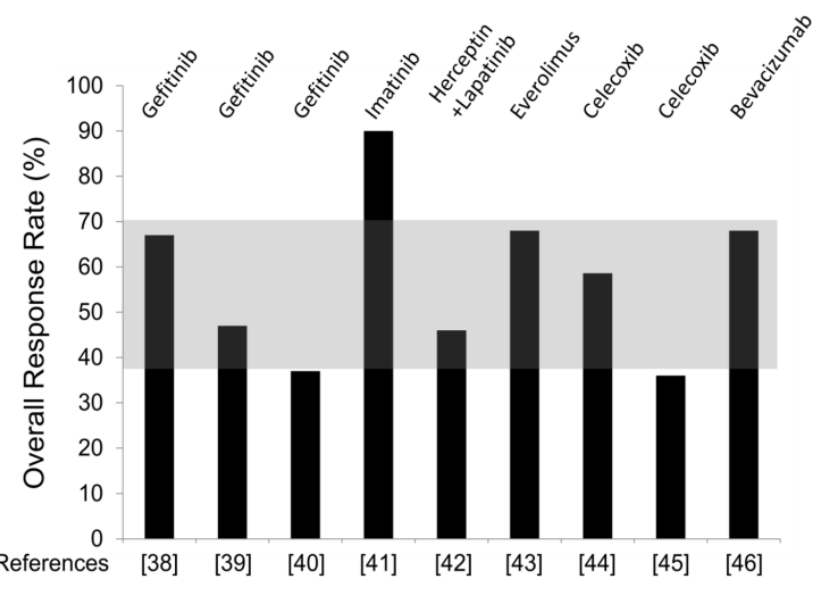

Fig. 2. Overall Response Rate (RR) observed combining Al and targeted agents in the selected trials. The targeted agents utilized in each study are specified in the top. Reference number is placed in the bottom. The shaded area comprised between $37 \%$ and $70 \%$ depicts the range of RR observed with $\mathrm{Al}$ alone in historical studies.

Second, tumor in the neoadjuvant setting is different from tumor in the metastatic disease given that the former has never been exposed to chemo/hormonal therapies. This issue is particularly important for the mTOR pathway that seems to be mostly activated in the mechanism of acquired resistance to AI [48]. This is probably one of the reasons for the benefit of everolimus added to AIs in patients previously treated with AIs [37] and, on the contrary, may partially explain the absence of benefit of temsirolimus, another mTOR inhibitor, in a setting of AI-naïve patients $[49,50]$.

Third, the hypothesis generating the clinical study might be not true. This is probably the case of celecoxib, a COX-2 inhibitor. The biological rationale to add celecoxib to AIs is that breast cancer self-production of estrogen is relevant for tumor growth. Prostaglandin E2 (PGE2), produced by COX-2, determines high levels of intratumoral estrogen by increasing intracellular cAMP that, in turns, enhances aromatase enzyme synthesis. COX-2 overexpression, high levels of PGE2 and increased aro- 
matase activity have been observed in breast cancer $[51,52]$. However, the contribution of tumor synthesized estrogens to the breast cancer estrogen levels is negligible compared to systemic production. Intratumoral estrogens come mainly by circulatory uptake and, therefore, reflect plasma estrogen concentration [53]. For this reason reducing local estrogen synthesis could be not effective.

Finally, the duration of treatment might be too short. It has been reported that the longer is the neoadjuvant endocrine treatment the higher is the overall RR [54]. Rimawi et al. (S. Antonio 2014) showed that longer treatment with dual anti-HER2 therapy (trastuzumab plus lapatinib) in combination with endocrine therapy and without chemotherapy leads to a meaningful increase in pCR rate in HR+/HER2+ breast cancer ( $33 \%$ with 24 weeks vs $9 \%$ with 12 weeks of therapy) [55]. In most of the presented studies, patients were treated for no more than 4 months, and in some cases for just a few weeks.

Furthermore, RR might not be the only indicator of efficacy, especially for long-term outcome. Parameters such as Ki67 reduction, depth of response, or achievement of $\mathrm{pCR}$ could be relevant in regimens containing targeted agents. A significant reduction in Ki67 was observed adding gefitinib [38] or everolimus [43] to AI. Moreover, high rates of pCR were reported using AI with trastuzumab/lapatinib or bevacizumab, $18 \%$ and $13 \%$ respectively. This is particularly impressive for a nonchemotherapy-containing regimen, considering that hormone therapy alone rarely achieves pCR [56-58]. At the moment we do not know if the higher rates of Ki67 reduction or pCR observed with these targeted therapies might translate in a better clinical outcome.

In conclusion, thus far, in the breast cancer neoadjuvant setting, the attempts to increase endocrine response by targeting specific intracellular pathways have been disappointing. Further studies are needed for a better knowledge of the complex mechanisms responsible for "de novo" or acquired hormone resistance. The identification of a specific molecular target and a strict selection of HR-positive patients to treat are still the future challenge to improve endocrine responsiveness.

\section{Abbreviations}

AI: aromatase inhibitor; BCS: breast conserving surgery; CR: complete response; EGFR: epidermal growth factor receptor; HER2: human epidermal growth factor receptor 2; HR: hormone receptor; mTOR: mammalian target of rapamycin; PD: progressive disease; pCR: pathologic complete response; PDGFR: platelet-derived growth factor receptor; PR: partial response; RR: response rate; SD: stable disease;
TKR: tyrosine kinase receptor; VEGF: vascular endothelial growth factor.

\section{Acknowledgments}

This work was supported from the Consorzio Interuniversitario Nazionale per la Bio-Oncologia (CINBO) and institutional funding from ' $\mathrm{G}$. D’Annunzio' University.

\section{Competing interests} interest.

The authors declare that they have no competing

\section{References}

1. Hortobagyi GN, Ames FC, Buzdar AU, Kau SW, McNeese MD, Paulus D, Hug V, Holmes FA, Romsdahl MM, Fraschini G, et al. Management of stage III primary breast cancer with primary chemotherapy, surgery, and radiation therapy. Cancer. 1988; 62:2507-16.

2. Danforth DN Jr, Lippman ME, McDonald H, Bader J, Egan E, Lampert M, Steinberg SM, Swain SM. Effect of preoperative chemotherapy on mastectomy for locally advanced breast cancer. Am Surg. 1990; 56:6-11.

3. Schwartz GF, Birchansky CA, Komarnicky LT, Mansfield CM, Cantor RI, Biermann WA, Fellin FM, McFarlane J. Induction chemotherapy followed by breast conservation for locally advanced carcinoma of the breast. Cancer. 1994; 73:362-69.

4. Fisher B, Brown A, Mamounas E, Wieand S, Robidoux A, Margolese RG, Cruz AB, Jr., Fisher ER, Wickerham DL, Wolmark N, DeCillis A, Hoehn JL, Lees AW, Dimitrov NV. Effect of preoperative chemotherapy on local-regional disease in women with operable breast cancer: findings from National Surgical Adjuvant Breast and Bowel Project B-18. J Clin Oncol. 1997; 15:2483-93.

5. van der Hage JA, van de Velde CJ, Julien JP, Tubiana-Hulin M, Vandervelden C, Duchateau L. Preoperative chemotherapy in primary operable breast cancer: results from the European Organization for Research and Treatment of Cancer trial 10902. J Clin Oncol. 2001;19:4224-37.

6. Semiglazov V, Eiermann W, Zambetti M, Manikhas A, Bozhok A, Lluch A, Tjulandin S, Sabadell MD, Caballero A, Valagussa P, Baselga J, Gianni L. Surgery following neoadjuvant therapy in patients with HER2-positive locally advanced or inflammatory breast cancer participating in the NeOAdjuvant Herceptin (NOAH) study. Eur J Surg Oncol. 2011; 37:856-63.

7. Mauri D, Pavlidis N, Ioannidis JP. Neoadjuvant versus adjuvant systemic treatment in breast cancer: a meta-analysis. J Natl Cancer Inst. 2005; 97:188-94.

8. Bear HD, Anderson S, Smith RE, Geyer CE Jr, Mamounas EP, Fisher B, Brown AM, Robidoux A, Margolese R, Kahlenberg MS, Paik S, Soran A, Wickerham DL, Wolmark N. Sequential preoperative or postoperative docetaxel added to preoperative doxorubicin plus cyclophosphamide for operable breast cancer: National Surgical Adjuvant Breast and Bowel Project Protocol B-27. J Clin Oncol. 2006; 24:2019-27.

9. Mieog JS, van der Hage JA, van de Velde CJ. Neoadjuvant chemotherapy for operable breast cancer. Br J Surg. 2007; 94:1189-200.

10. Kuerer HM, Newman LA, Smith TL, Ames FC, Hunt KK, Dhingra K, Theriault RL, Singh G, Binkley SM, Sneige N, Buchholz TA, Ross MI, McNeese MD, Buzdar AU, Hortobagyi GN, Singletary SE. Clinical course of breast cancer patients with complete pathologic primary tumor and axillary lymph node response to doxorubicin-based neoadjuvant chemotherapy. J Clin Oncol. 1999; 17:460-9.

11. Kaufmann M, Hortobagyi GN, Goldhirsch A, Scholl S, Makris A, Valagussa P, Blohmer JU, Eiermann W, Jackesz R, Jonat W, Lebeau A, Loibl S, Miller W, Seeber S, Semiglazov V, Smith R, Souchon R, Stearns V, Untch M, von Minckwitz G. Recommendations from an international expert panel on the use of neoadjuvant (primary) systemic treatment of operable breast cancer: an update. J Clin Oncol. 2006; 24:1940-9.

12. Colleoni M, Bagnardi V, Rotmensz N, Gelber RD, Viale G, Pruneri G, Veronesi P, Torrisi R, Cardillo A, Montagna E, Campagnoli E, Luini A, Intra M, Galimberti V, Scarano E, Peruzzotti G, Goldhirsch A. Increasing steroid hormone receptors expression defines breast cancer subtypes non responsive to preoperative chemotherapy. Breast Cancer Res Treat. 2009; 116:359-69.

13. Huober J, von Minckwitz G, Denkert C, Tesch H, Weiss E, Zahm DM, Belau A, Khandan F, Hauschild M, Thomssen C, Hogel B, Darb-Esfahani S, Mehta K, Loibl S. Effect of neoadjuvant anthracycline-taxane-based chemotherapy in different biological breast cancer phenotypes: overall results from the GeparTrio study. Breast Cancer Res Treat. 2010; 124:133-40.

14. Precht LM, Lowe KA, Atwood M, Beatty JD. Neoadjuvant chemotherapy of breast cancer: tumor markers as predictors of pathologic response, recurrence, and survival. Breast J. 2010; 16:362-68

15. Straver ME, Rutgers EJ, Rodenhuis S, Linn SC, Loo CE, Wesseling J, Russell NS, Oldenburg HS, Antonini N, Vrancken Peeters MT. The relevance of breast 
cancer subtypes in the outcome of neoadjuvant chemotherapy. Ann Surg Oncol. 2010; 17:2411-18.

16. Kim SI, Sohn J, Koo JS, Park SH, Park HS, Park BW. Molecular subtypes and tumor response to neoadjuvant chemotherapy in patients with locally advanced breast cancer. Oncology. 2010; 79:324-30.

17. von Minckwitz G, Untch M, Blohmer JU, Costa SD, Eidtmann H, Fasching PA, Gerber B, Eiermann W, Hilfrich J, Huober J, Jackisch C, Kaufmann M, Konecny GE, Denkert C, Nekljudova V, Mehta K, Loibl S. Definition and impact of pathologic complete response on prognosis after neoadjuvant chemotherapy in various intrinsic breast cancer subtypes. J Clin Oncol. 2012; 30:1796-804.

18. Eiermann W, Paepke S, Appfelstaedt J, Llombart-Cussac A, Eremin J, Vinholes J, Mauriac L, Ellis M, Lassus M, Chaudri-Ross HA, Dugan M, Borgs M. Preoperative treatment of postmenopausal breast cancer patients with letrozole: A randomized double-blind multicenter study. Ann Oncol. 2001; 12:1527-32.

19. Smith IE, Dowsett M, Ebbs SR, Dixon JM, Skene A, Blohmer JU, Ashley SE, Francis S, Boeddinghaus I, Walsh G. Neoadjuvant treatment of postmenopausal breast cancer with anastrozole, tamoxifen, or both in combination: the Immediate Preoperative Anastrozole, Tamoxifen, or Combined with Tamoxifen (IMPACT) multicenter double-blind randomized trial. J Clin Oncol. 2005; 23:5108-16.

20. Cataliotti L, Buzdar AU, Noguchi S, Bines J, Takatsuka Y, Petrakova K, Dube $\mathrm{P}$, de Oliveira CT. Comparison of anastrozole versus tamoxifen as preoperative therapy in postmenopausal women with hormone receptor-positive breast cancer: the Pre-Operative "Arimidex" Compared to Tamoxifen (PROACT) trial. Cancer. 2006; 106:2095-103.

21. Masuda N, Sagara Y, Kinoshita T, Iwata H, Nakamura S, Yanagita Y, Nishimura R, Iwase H, Kamigaki S, Takei H, Noguchi S. Neoadjuvant anastrozole versus tamoxifen in patients receiving goserelin for premenopausal breast cancer (STAGE): a double-blind, randomised phase 3 trial. Lancet Oncol. 2012; 13:345-52.

22. Nicholson RI, McClelland RA, Robertson JF, Gee JM. Involvement of steroid hormone and growth factor cross-talk in endocrine response in breast cancer. Endocr Relat Cancer. 1999; 6:373-87.

23. Johnston SR. Combinations of endocrine and biological agents: present status of therapeutic and presurgical investigations. Clin Cancer Res. 2005; $11: 889 \mathrm{~s}-99 \mathrm{~s}$

24. Benz CC, Scott GK, Sarup JC, Johnson RM, Tripathy D, Coronado E, Shepard $\mathrm{HM}$, Osborne CK. Estrogen-dependent, tamoxifen-resistant tumorigenic growth of MCF-7 cells transfected with HER2/neu. Breast Cancer Res Treat. 1992; 24:85-95

25. Pietras RJ, Arboleda J, Reese DM, Wongvipat N, Pegram MD, Ramos L, Gorman CM, Parker MG, Sliwkowski MX, Slamon DJ. HER-2 tyrosine kinase pathway targets estrogen receptor and promotes hormone-independent growth in human breast cancer cells. Oncogene. 1995; 10:2435-46.

26. Shin I, Miller T, Arteaga CL. ErbB receptor signaling and therapeutic resistance to aromatase inhibitors. Clin Cancer Res. 2006; 12:1008s-12s.

27. Arpino G, Green SJ, Allred DC, Lew D, Martino S, Osborne CK, Elledge RM. HER-2 amplification, HER-1 expression, and tamoxifen response in estrogen receptor-positive metastatic breast cancer: a southwest oncology group study. Clin Cancer Res. 2004; 10:5670-6.

28. Carvalho I, Milanezi F, Martins A, Reis RM, Schmitt F. Overexpression of platelet-derived growth factor receptor alpha in breast cancer is associated with tumour progression. Breast Cancer Res. 2005; 7:R788-95.

29. Clark AS, West K, Streicher S, Dennis PA. Constitutive and inducible Akt activity promotes resistance to chemotherapy, trastuzumab, or tamoxifen in breast cancer cells. Mol Cancer Ther. 2002; 1:707-17.

30. Miller TW, Balko JM, Arteaga CL. Phosphatidylinositol 3-kinase and antiestrogen resistance in breast cancer. J Clin Oncol. 2011; 29:4452-61.

31. Ou Z, Van Ginkel S, Roy AM, Westbrook L, Nasrin M, Maxuitenko Y, Frost AR, Carey D, Wang W, Li R, Grizzle WE, Thottassery JV, Kern FG. Vascular endothelial growth factor reduces tamoxifen efficacy and promotes metastatic colonization and desmoplasia in breast tumors. Cancer Res. 2008; 68:6232-40.

32. Gee JM, Harper ME, Hutcheson IR, Madden TA, Barrow D, Knowlden JM, McClelland RA, Jordan N, Wakeling AE, Nicholson RI. The antiepidermal growth factor receptor agent gefitinib (ZD1839/Iressa) improves antihormone response and prevents development of resistance in breast cancer in vitro. Endocrinology. 2003; 144:5105-17.

33. Nicholson RI, Hutcheson IR, Knowlden JM, Jones HE, Harper ME, Jordan N, Hiscox SE, Barrow D, Gee JM. Nonendocrine pathways and endocrine resistance: observations with antiestrogens and signal transduction inhibitors in combination. Clin Cancer Res. 2004; 10:346s-54s.

34. deGraffenried LA, Friedrichs WE, Russell DH, Donzis EJ, Middleton AK, Silva JM, Roth RA, Hidalgo M. Inhibition of mTOR activity restores tamoxifen response in breast cancer cells with aberrant Akt Activity. Clin Cancer Res. 2004; 10:8059-67.

35. Kaufman B, Mackey JR, Clemens MR, Bapsy PP, Vaid A, Wardley A, Tjulandin S, Jahn M, Lehle M, Feyereislova A, Revil C, Jones A. Trastuzumab plus anastrozole versus anastrozole alone for the treatment of postmenopausal women with human epidermal growth factor receptor 2-positive, hormone receptor-positive metastatic breast cancer: results from the randomized phase III TAnDEM study. J Clin Oncol. 2009; 27:5529-37.

36. Johnston S, Pippen J, Jr., Pivot X, Lichinitser M, Sadeghi S, Dieras V, Gomez HL, Romieu G, Manikhas A, Kennedy MJ, Press MF, Maltzman J, Florance A, O'Rourke L, Oliva C, Stein S, Pegram M. Lapatinib combined with letrozole versus letrozole and placebo as first-line therapy for postmenopausal hormone receptor-positive metastatic breast cancer. J Clin Oncol. 2009; 27:5538-46.

37. Baselga J, Campone M, Piccart M, Burris HA, 3rd, Rugo HS, Sahmoud T, Noguchi S, Gnant M, Pritchard KI, Lebrun F, Beck JT, Ito Y, Yardley D, Deleu I, Perez A, Bachelot T, Vittori L, Xu Z, Mukhopadhyay P, Lebwohl D, Hortobagyi GN. Everolimus in postmenopausal hormone-receptor-positive advanced breast cancer. N Engl J Med. 2012; 366:520-9.

38. Polychronis A, Sinnett HD, Hadjiminas D, Singhal H, Mansi JL, Shivapatham D, Shousha S, Jiang J, Peston D, Barrett N, Vigushin D, Morrison K, Beresford E, Ali S, Slade MJ, Coombes RC. Preoperative gefitinib versus gefitinib and anastrozole in postmenopausal patients with oestrogen-receptor positive and epidermal-growth-factor-receptor-positive primary breast cancer: a double-blind placebo-controlled phase II randomised trial. Lancet Oncol. 2005; 6:383-91.

39. Smith IE, Walsh G, Skene A, Llombart A, Mayordomo JI, Detre S, Salter J, Clark E, Magill P, Dowsett M. A phase II placebo-controlled trial of neoadjuvant anastrozole alone or with gefitinib in early breast cancer. J Clin Oncol. 2007; 25:3816-22.

40. Massarweh S, Tham YL, Huang J, Sexton K, Weiss H, Tsimelzon A, Beyer A, Rimawi M, Cai WY, Hilsenbeck S, Fuqua S, Elledge R. A phase II neoadjuvant trial of anastrozole, fulvestrant, and gefitinib in patients with newly diagnosed estrogen receptor positive breast cancer. Breast Cancer Res Treat. 2011; 129:819-27.

41. Chow LW, Yip AY, Loo WT, Toi M. Evaluation of neoadjuvant inhibition of aromatase activity and signal transduction in breast cancer. Cancer Lett. 2008; 262:232-8

42. Rimawi MF, Mayer IA, Forero A, Nanda R, Goetz MP, Rodriguez AA, Pavlick AC, Wang T, Hilsenbeck SG, Gutierrez C, Schiff R, Osborne CK, Chang JC. Multicenter phase II study of neoadjuvant lapatinib and trastuzumab with hormonal therapy and without chemotherapy in patients with human epidermal growth factor receptor 2-overexpressing breast cancer: TBCRC 006. J Clin Oncol. 2013; 31:1726-31.

43. Baselga J, Semiglazov V, van Dam P, Manikhas A, Bellet M, Mayordomo J, Campone M, Kubista E, Greil R, Bianchi G, Steinseifer J, Molloy B, Tokaji E, Gardner H, Phillips P, Stumm M, Lane HA, Dixon JM, Jonat W, Rugo HS. Phase II randomized study of neoadjuvant everolimus plus letrozole compared with placebo plus letrozole in patients with estrogen receptor-positive breast cancer. J Clin Oncol. 2009; 27:2630-7.

44. Chow LW, Yip AY, Loo WT, Lam CK, Toi M. Celecoxib anti-aromatase neoadjuvant (CAAN) trial for locally advanced breast cancer. J Steroid Biochem Mol Biol. 2008; 111:13-17.

45. Lustberg MB, Povoski SP, Zhao W, Ziegler RM, Sugimoto Y, Ruppert AS, Lehman AM, Shiels DR, Mrozek E, Ramaswamy B, Layman RM, Brueggemeier RW, Shapiro CL. Phase II trial of neoadjuvant exemestane in combination with celecoxib in postmenopausal women who have breast cancer. Clin Breast Cancer. 2011; 11:221-7.

46. Forero-Torres A, Saleh MN, Galleshaw JA, Jones CF, Shah JJ, Percent IJ, Nabell LM, Carpenter JT, Falkson CI, Krontiras H, Urist MM, Bland KI, De Los Santos JF, Meredith RF, Caterinicchia V, Bernreuter WK, O'Malley JP, Li Y, LoBuglio AF. Pilot trial of preoperative (neoadjuvant) letrozole in combination with bevacizumab in postmenopausal women with newly diagnosed estrogen reeptor- or progesterone receptor-positive breast cancer. Clin Breast Cancer. $2010 ; 10: 275-80$

47. Grassadonia A, Di Nicola M, Grossi S, Noccioli P, Tavoletta S, Politi R, Angelucci D, Marinelli C, Zilli M, Ausili Cefaro G, Tinari N, De Tursi M, Iezzi L, Cioffi P, Iacobelli S, Natoli C, Cianchetti E. Long-term outcome of neoadjuvant endocrine therapy with aromatase inhibitors in elderly women with hormone receptor-positive breast cancer. Ann Surg Oncol. 2014; 21:1575-82.

48. Cavazzoni A, Bonelli MA, Fumarola C, La Monica S, Airoud K, Bertoni R, Alfieri RR, Galetti M, Tramonti S, Galvani E, Harris AL, Martin LA, Andreis D, Bottini A, Generali D, Petronini PG. Overcoming acquired resistance to letrozole by targeting the PI3K/AKT/mTOR pathway in breast cancer cell clones. Cancer Lett. 2012; 323:77-87.

49. Chow LWC SY, Jassem J. Phase 3 study of temsirolimus with letrozole or letrozole alone in postmenopausal women with locally advanced or metastatic breast cancer. Breast Cancer Res Treat. 2006; 100 (suppl 1): abstr6091.

50. Wolff AC, Lazar AA, Bondarenko I, Garin AM, Brincat S, Chow L, Sun Y, Neskovic-Konstantinovic Z, Guimaraes RC, Fumoleau P, Chan A, Hachemi S, Strahs A, Cincotta M, Berkenblit A, Krygowski M, Kang LL, Moore L, Hayes DF. Randomized phase III placebo-controlled trial of letrozole plus oral temsirolimus as first-line endocrine therapy in postmenopausal women with locally advanced or metastatic breast cancer. J Clin Oncol. 2013; 31:195-202.

51. Badawi AF, Badr MZ. Expression of cyclooxygenase-2 and peroxisome proliferator-activated receptor-gamma and levels of prostaglandin E2 and 15-deoxy-delta12,14-prostaglandin $\mathrm{J} 2$ in human breast cancer and metastasis. Int J Cancer. 2003; 103:84-90.

52. Brueggemeier RW, Quinn AL, Parrett ML, Joarder FS, Harris RE, Robertson FM. Correlation of aromatase and cyclooxygenase gene expression in human breast cancer specimens. Cancer Lett. 1999; 140:27-35.

53. Lonning PE, Haynes BP, Straume AH, Dunbier A, Helle H, Knappskog S, Dowsett M. Exploring breast cancer estrogen disposition: the basis for endocrine manipulation. Clin Cancer Res. 2011; 17:4948-58.

54. Allevi G, Strina C, Andreis D, Zanoni V, Bazzola L, Bonardi S, et al. Increased pathological complete response rate after a long-term neoadjuvant letrozole 
treatment in postmenopausal oestrogen and/or progesterone receptor-positive breast cancer. Br J Cancer. 2013; 108:1587-92.

55. Rimawi MF, Niravath PA, Wang T, et al. TBCRC023: A randomized multicenter phase II neoadjuvant trial of lapatinib plus trastuzumab, with endcorine therapy and without chemotherapy, for 12 vs. 24 weeks in patients with HER2 overexpressing breast cancer. San Antonio Breast Cancer Symposium (SABCS) 2014;: S6-02.

56. Gruenberger T, Gorlitzer M, Soliman T, Rudas M, Mittlboeck M, Gnant M, Reiner A, Teleky B, Seitz W, Jakesz R. It is possible to omit postoperative irradiation in a highly selected group of elderly breast cancer patients. Breast Cancer Res Treat. 1998; 50:37-46.

57. Berruti A, Generali D, Kaufmann M, Puztai L, Curigliano G, Aglietta M, Gianni L, Miller WR, Untch M, Sotiriou C, Daidone M, Conte P, et al. A International expert consensus on primary systemic therapy in the management of early breast cancer: highlights of the Fourth Symposium on Primary Systemic Therapy in the Management of Operable Breast Cancer, Cremona, Italy (2010). J Natl Cancer Inst Monogr. 2011; 2011:147-51.

58. Zambetti M, Mansutti M, Gomez P, Lluch A, Dittrich C, Zamagni C, Ciruelos E, Pavesi L, Semiglazov V, De Benedictis E, Gaion F, Bari M, Morandi P, Valagussa P, Luca G. Pathological complete response rates following different neoadjuvant chemotherapy regimens for operable breast cancer according to ER status, in two parallel, randomized phase II trials with an adaptive study design (ECTO II). Breast Cancer Res Treat. 2012; 132:843-51. 